\title{
Synoptic weather patterns and modification of the association between air pollution and human mortality
}

\author{
DANIEL G. C. RAINHAM ${ }^{1}$, KAREN E. SMOYER-TOMIC ${ }^{2}$, \\ SCOTT C. SHERIDAN ${ }^{3}$, \& RICHARD T. BURNETT ${ }^{4}$ \\ ${ }^{1}$ University of Ottawa, Ottawa, Ontario, Canada, ${ }^{2}$ University of Alberta, Edmonton, Alberta, Canada, \\ ${ }^{3}$ Kent State University, Kent, Ohio, USA, and ${ }^{4}$ Health Canada, Ottawa, Ontario, Canada
}

\begin{abstract}
To assess whether meteorological conditions modify the relationship between short-term exposure to ambient air pollution and mortality, an examination of air pollution and human mortality associations (ecologic) using hybrid spatial synoptic classification procedures was conducted. Concentrations of air pollutants and human mortality from all non-accidental and cardiorespiratory causes were examined according to typical winter and summer synoptic climatologies in Toronto, Canada, between 1981 and 1999. Air masses were derived using a hybrid spatial synoptic classification procedure associating each day over the 19-year period with one of six different typical weather types, or a transition between two weather types. Generalized linear models (GLMs) were used to assess the risk of mortality from air pollution within specific air mass type subsets. Mortality follows a distinct seasonal pattern with a maximum in winter and a minimum in summer. Average air pollution concentrations were similar in both seasons with the exception of elevated sulfur dioxide levels in winter and elevated ozone levels in summer. Subtle changes in meteorological composition can alter the strength of pollutant associations with health outcomes, especially in the summer season. Although there does not appear to be any systematic patterning of modification, variation in pollutant concentrations seems dependent on the type of synoptic category present.
\end{abstract}

Keywords: Air pollution, meteorological factors, mortality, Canada

Abbreviations: $\mathrm{CO}$, carbon monoxide; $\mathrm{NO}_{2}$, nitrogen dioxide; $\mathrm{SO}_{2}$, sulphur dioxide; $\mathrm{O}_{3}$, ozone; $\mathrm{PM}_{2.5}$, particulate matter $<2.5$ microns in aerodiameter; GLM, generalized linear model; AIC, Akaike's Information Criterion; DM, dry moderate; DP, dry polar; DT, dry tropical; MM, moist moderate; MP, moist polar; MT, moist tropical; TR, transitional; SLP, sea level pressure; $\mathrm{T}_{\mathrm{a}}$, drybulb temperature; $T_{d}$, dew point temperature.

\section{Introduction}

Numerous epidemiological studies have reported daily and seasonal mortality fluctuations to be positively and significantly associated with atmospheric pollution and meteorological variables such as temperature and barometric pressure, although less is known about the

Correspondence: Daniel Rainham, McLaughlin Centre for Population Health Risk Assessment, Institute of Population Health, University of Ottawa, One Stewart Street, Ottawa, K1N 6N5, Canada. Tel: +1 613562 5800, ext. 2092. Fax: +1 6135625380. E-mail: drain067@uottawa.ca 
health risk from atmospheric pollutants in the context of frequently occurring weather patterns. Typical time-series investigations of health risk from air pollution or thermal stress statistically control for potential confounders in regression equations. For example, two studies of the association between air pollution and mortality covering thirty-one North American cities controlled for the confounding effects of weather by including temperature or a temperature-related index in the models (Burnett et al. 1998b; Samet et al. 2000). Similarly, investigations of the health effects from thermal stress, such as heat or cold waves, often include some variable to control for the effect of air pollution (O'Neill et al. 2003; Pattenden et al. 2003; Rainham \& Smoyer-Tomic 2003).

Air pollution dispersion patterns and concentration are generally weather-driven (Flemming 1996) and vary with anthropogenic emissions. Several studies have shown temperature to positively influence several common urban air pollutants (Gotoh 1993; Niccum et al. 1995), yet the potential for air pollution or meteorological variables to confound and/or modify mortality risk estimates remains uncertain. For example, studies have reported synergistic temperature/air pollution effects on health when temperatures are unusually cool (Lebowitz et al. 1973), or warm (Katsouyanni et al. 1993; Wyzga \& Lipfert 1994; Styer et al. 1995; Choi et al. 1997). The limited number of studies and inconsistent results necessitate further research on how weather affects the association between air pollution and mortality.

Synoptic climatological approaches, as an alternative to traditional descriptive methods for examining individual weather variables, group weather patterns according to similar and frequently occurring meteorological complexes (Kalkstein et al. 1987). Studies have used synoptic methods to confirm associations between respirable particles and mortality (Pope \& Kalkstein 1996), to estimate the impact of climate change on human health (Kalkstein \& Greene 1997), to aid in the forecast of air pollution episodes (Lam \& Cheng 1998), and to explore air pollution effects on human mortality during extreme weather conditions (Smoyer et al. 2000). Developing knowledge of the role of weather in environment and health relationships may lead to enhanced understanding of the potential health effects arising from global climate change. Synoptic approaches have proven useful in biometeorological applications since organisms generally respond to ambient atmospheric conditions rather than to individual variables such as temperature and atmospheric pressure.

The aim of this study is to evaluate the applicability of a synoptic approach to assess the short term association between air pollution and mortality in Toronto, Canada. Toronto is Canada's largest city, with approximately 4.4 million people in the greater metropolitan area and is situated on the north shore of Lake Ontario $\left(43^{\circ} 40^{\prime} \mathrm{N}\right)$. We assess the variability of air pollution and mortality, and also produce mortality risk estimates from ambient air pollution among air mass types typical of winter and summer seasons, when weather is most likely to modify the air pollution and health relationship. Thus our study investigates whether mortality risk from air pollution differs by season and by air mass type.

\section{Method}

Mortality, weather, and air pollution data

We assembled 19 years of daily counts of non-trauma mortality, weather and air pollution concentration data. Mortality data collected from Statistics Canada were grouped into total (ICD9: < 800), cardiorespiratory (ICD9: 390-459; 480-519), and non-cardiorespiratory ('other') deaths. Meteorological data used for the development of synoptic air mass categories are distributed by the Meteorological Service of Canada from a station at the Toronto Pearson International Airport, located approximately $15 \mathrm{~km}$ west of the urban core. The Ontario 
Ministry of the Environment provided hourly average concentrations of carbon monoxide, nitrogen dioxide, sulphur dioxide, ozone, and fine particles $\left(\mathrm{PM}_{2.5}\right)$ from monitoring sites not influenced by local source pollution. Daily $\mathrm{PM}_{2.5}$ data was constructed from daily $\mathrm{SO}_{4}$ and coefficient of haze data by calibrating it to $\mathrm{PM}_{2.5}$ data sampled every sixth day. These measurements were averaged to obtain a daily time series for each pollutant.

\section{Creation of synoptic weather categories}

The spatial synoptic classification (SSC) system is a semi-automated statistical approach designed to classify complex daily weather conditions into one of six distinct categories, or a transitional category which represents a day when one weather category yields to another. To discriminate among weather categories we used values of temperature, dew point, $u$ (eastwest) and v (north-south) components of wind, cloud cover, and sea level pressure collected daily at 4,10, 16 and $22 \mathrm{~h}$ EST. A detailed explanation of the categorization process can be found elsewhere (Sheridan 2002).

\section{Analysis}

Data analysis was conducted in two stages. First, we calculated mean (and standard deviation) values of mortality and air pollution for each of the seven synoptic air mass categories for winter (December-February) and summer (June-August). Lag effects were examined by evaluating the type of air mass on the day of death, as well as one and two days prior. Limiting the analysis to these observations helps to ameliorate potential bias resulting from selective reporting of lags related to the largest effect estimates and corresponds more closely to the acute nature of atmospheric health risks. Two-tailed $t$-tests were used to ascertain whether particular air masses have atypical values of mortality or pollutant concentrations.

In the second stage of the analysis we explored potential modification of the association between air pollution and mortality using a standardized approach to the specification of loglinear models with Poisson error to assess the effects of air pollution while accounting for influential temporal trends using a parametric method. Natural splines were used to manage serial autocorrelation in the mortality data and to model various combinations of air pollutants and lag structures. A combination of procedures, including partial autocorrelation plots, a modified Bartlett's Test (to examine residual structures), and Akaike's Information Criterion (AIC), were used to explore the relation between mortality and potential time related confounders. Based on these diagnostics we selected eight degrees of freedom per year for total and cardiorespiratory mortality and six degrees of freedom for all other mortality outcomes for a total of $152 d f$ and $114 d f$ respectively over the 19 years of record. We considered parametrically smoothed functions of air pollution for the same day and up to the previous two days, each with between two to six degrees of freedom. Factor variables were also included to control for variation in mortality on different days of the week and during winter and summer holidays.

Separate models were run for each pollutant, for each air mass and by season. The final model formulation has the form below:

$$
E\left[\log \left(Y_{i}\right)\right]=a+n s\left(d a y_{i}, d f\right)+d o w+n s\left(a p_{i}, d f\right)
$$

where $Y_{i}$ is the number of deaths on day $i,\left(d a y_{\mathrm{i}}\right)$ specifies the day in the time series, dow is a factor variable to control for day-of-week variability in mortality, $a p_{i}$ represents air pollution 
on day $i$, and where the (per year) degrees of freedom ( $d f$ ) specifies the smoothness of the parameter in the model. Accordingly we ran a total of 35 regressions for each season and for each type of mortality outcome. The aggregate models were fit using the $\operatorname{glm}()$ function in S-Plus 6.1 software (S-Plus for Windows, Seattle, WA) using a stringent convergence tolerance $\left(1 \mathrm{e}^{-15}\right.$ ) and a limit of 1000 iterations (Dominici et al. 2002; Ramsey et al. 2002).

\section{Results}

Concentrations of most air pollutants declined over time, except for ozone which has both increased in concentration and in variability over the 19 year period. Pollutant levels associated with transportation and combustion were higher in winter than summer. Fine particle concentrations were slightly elevated in summer, and ozone concentrations were 2.5 times higher in summer than in winter. Seasonal variations were also found for all mortality outcomes, typically with more deaths in winter than in summer (Table I).

\section{Air pollution and mortality relationships by season}

Winter. Most winters are characterized by the dry polar air mass (32\% of all winter days) and distinguished by cold, dry air, northerly winds and little to no cloud cover suggesting a dominant high pressure system with northern Canadian origins (Table II). Interestingly, the coldest air mass (DP) had significantly lower mortality than the other air masses (Table III). Mortality was highest during transition (TR) days (Table III), characterized by variable, inclement, and windy weather, typical of frontal passages (Table II). Despite their different mortality rates, both air masses had relatively lower pollutant concentrations than the other winter categories, especially the TR air mass (Table III). Pollutant concentrations in the remaining air masses varied. The MP air mass, typically resulting in cloudy, windy and wet conditions, had consistently lower air pollution than other air masses. Pollutants associated with transportation and energy production, such as $\mathrm{NO}_{2}$ and $\mathrm{SO}_{2}$ were higher during $\mathrm{DM}$ air masses (Table III), which typically involve the advection of warm Pacific air. Elevated $\mathrm{O}_{3}$ concentrations occurred with the presence of DP air masses (Table III), which are characteristically cool, sunny and calm, conditions conducive to photoreactive processes.

Table I. Mean and standard deviations for air pollution, weather and mortality data.

\begin{tabular}{|c|c|c|c|}
\hline & All years & Winters (Dec-Feb) & Summers (June-Aug) \\
\hline $\mathrm{CO}(\mathrm{ppm})$ & $1.3(0.6)$ & $1.3(0.5)$ & $1.3(0.5)$ \\
\hline $\mathrm{NO}_{2}(\mathrm{ppb})$ & $25.6(8.3)$ & $26.4(7.4)$ & $24.8(8.1)$ \\
\hline $\mathrm{SO}_{2}(\mathrm{ppb})$ & $4.8(4.2)$ & $6.7(5.8)$ & $3.6(2.6)$ \\
\hline $\mathrm{O}_{3}(\mathrm{ppb})$ & $17.3(9.7)$ & $10.6(5.6)$ & $25.2(10.2)$ \\
\hline $\mathrm{PM}_{2.5}\left(\mu \mathrm{g} / \mathrm{m}^{3}\right)$ & $17.0(8.7)$ & $17.2(6.8)$ & $18.8(10.2)$ \\
\hline Temperature $\left({ }^{\circ} \mathrm{C}\right)$ & $8.1(10.5)$ & $-3.9(5.9)$ & $20.1(3.6)$ \\
\hline Dew-point $\left({ }^{\circ} \mathrm{C}\right)$ & $3.0(9.7)$ & $-7.2(6.5)$ & $13.5(4.2)$ \\
\hline Sea-level pressure $(\mathrm{hPa})^{\star}$ & $1016.4(7.5)$ & $1017.6(8.9)$ & $1015.2(4.9)$ \\
\hline Cloud cover (tenths) & $6.3(2.9)$ & $7.3(2.8)$ & $5.4(2.8)$ \\
\hline Wind speed $(\mathrm{m} / \mathrm{s})$ & $3.4(2.0)$ & $3.9(2.1)$ & $2.7(1.6)$ \\
\hline Total mortality & $46.7(7.9)$ & $50.4(8.3)$ & $43.6(6.8)$ \\
\hline Cardiorespiratory & $22.2(5.4)$ & $24.9(5.8)$ & $19.8(4.6)$ \\
\hline Other mortality & $24.6(5.7)$ & $25.5(6.0)$ & $23.7(5.3)$ \\
\hline
\end{tabular}

${ }^{\star} \mathrm{hPa}=$ hectopascals (std. atmospheric pressure is approx. $1013.25 \mathrm{hPa}$ ). 
Table II. Meteorological composition ${ }^{\dagger}$ and qualitative description of winter and summer air mass types.

\begin{tabular}{|c|c|c|c|c|c|c|c|}
\hline Air Mass Category Description & Season & $\begin{array}{c}\text { Days } \\
(\%)\end{array}$ & $\begin{array}{c}\mathrm{T}_{\mathrm{a}} \\
\left({ }^{\circ} \mathrm{C}\right)\end{array}$ & $\begin{array}{l}\mathrm{T}_{\mathrm{d}} \\
\left({ }^{\circ} \mathrm{C}\right)\end{array}$ & $\begin{array}{l}\text { SLP } \\
(\mathrm{hPa})\end{array}$ & $\begin{array}{l}\text { Cloud } \\
\text { (10ths) }\end{array}$ & Winds` \\
\hline \multicolumn{8}{|l|}{ Dry Moderate } \\
\hline \multirow{2}{*}{$\begin{array}{l}\text { Mild, dry conditions. Usually } \\
\text { arises as modified DP air, or } \\
\text { with strong westerly flow aloft. }\end{array}$} & Winter & $210(12.3)$ & 0.5 & -3.9 & 1018.7 & 5.7 & Moderate, SW \\
\hline & Summer & $511(29.2)$ & 20.4 & 12.1 & 1017.2 & 3.9 & Moderate, NW \\
\hline \multicolumn{8}{|l|}{ Dry Polar } \\
\hline \multirow[b]{2}{*}{$\begin{array}{l}\text { Cold, clear, stable, and dry, } \\
\text { this air mass is typically } \\
\text { associated with } \\
\text { an anticyclone, north to } \\
\text { northwesterly flow aloft and } \\
\text { at the surface, and subsidence. }\end{array}$} & Winter & $550(32.1)$ & -9.8 & -13.8 & 1023.2 & 5.3 & Moderate, W \\
\hline & Summer & $257(14.7)$ & 15.9 & 7.7 & 1018.3 & 3.6 & Moderate, NW \\
\hline \multicolumn{8}{|l|}{ Dry Tropical } \\
\hline \multirow[b]{2}{*}{$\begin{array}{l}\text { Warm to hot, sunny, and dry } \\
\text { air mass; usually forms with } \\
\text { strong southwesterly advection } \\
\text { from southwestern US, or in situ } \\
\text { with significant subsidence aloft. }\end{array}$} & Winter & $1(0.0)$ & 7.9 & 0.7 & 1006.3 & 4.5 & Moderate, SW \\
\hline & Summer & $59(3.4)$ & 26.0 & 15.4 & 1015.1 & 3.6 & Moderate, W \\
\hline \multicolumn{8}{|l|}{ Moist Moderate } \\
\hline \multirow{2}{*}{$\begin{array}{l}\text { Mild, cloudy, unstable, showery. } \\
\text { Occurs in the vicinity of a warm } \\
\text { front, or as modified MP } \\
\text { (winter) or MT (summer) air. }\end{array}$} & Winter & $296(17.3)$ & 2.0 & 0.0 & 1012.8 & 9.5 & Moderate, SW \\
\hline & Summer & $344(19.7)$ & 19.4 & 15.8 & 1013.0 & 8.1 & Moderate, SE \\
\hline \multicolumn{8}{|l|}{ Moist Polar } \\
\hline \multirow[b]{2}{*}{$\begin{array}{l}\text { Cool, cloud, unstable with light } \\
\text { steady precipitation. Occurs with } \\
\text { advection from North Atlantic, } \\
\text { or with overrunning north of a } \\
\text { warm front. }\end{array}$} & Winter & $427(24.9)$ & -3.0 & -5.8 & 1015.1 & 9.0 & Moderate, W \\
\hline & Summer & $90(5.1)$ & 15.4 & 10.8 & 1013.7 & 7.7 & Moderate, NW \\
\hline \multicolumn{8}{|l|}{ Moist Tropical } \\
\hline \multirow[b]{2}{*}{$\begin{array}{l}\text { Very warm, unstable, with } \\
\text { significant convection. Arises } \\
\text { with strong southerly advection; } \\
\text { cloudy in winter, partly cloudy } \\
\text { in summer. }\end{array}$} & Winter & $21(1.2)$ & 8.2 & 6.7 & 1013.2 & 9.8 & Moderate, SW \\
\hline & Summer & $345(19.7)$ & 23.9 & 18.1 & 1013.7 & 5.8 & Moderate, W \\
\hline \multicolumn{8}{|l|}{ Transitional } \\
\hline \multirow{2}{*}{$\begin{array}{l}\text { A day in which one air mass } \\
\text { yields to another; usually } \\
\text { associated with a frontal passage. }\end{array}$} & Winter & $209(12.2)$ & -4.4 & -7.5 & 1014.7 & 7.7 & Moderate, W \\
\hline & Summer & $142(8.1)$ & 19.2 & 13.3 & 1011.6 & 6.3 & Moderate, NW \\
\hline
\end{tabular}

$T_{a}=$ dry-bulb temperature; $T_{d}=$ dew-point temperature. ${ }^{\dagger}$ Values for temperature, pressure and cloud cover are averages. ${ }^{\star}$ Wind speed is defined as: light: $0-2 \mathrm{~m} / \mathrm{s}$, moderate: $>2-5 \mathrm{~m} / \mathrm{s}$, strong: $>5 \mathrm{~m} / \mathrm{s}$; direction is approximated to nearest $45^{\circ}$.

The regression results provide more information about air pollution/mortality relations within synoptic categories. For the entire winter season, we saw little evidence of a relationship between air pollution and mortality (Table V). Only CO was positively, significantly associated with total mortality $(R R=1.005-1.044)$ for the winter season, and $\mathrm{NO}_{2}$ showed a similar but weaker relation with total mortality for the DM and TR air masses (Table V). The MT air mass, which occurs just $1.2 \%$ of the time, was the only air mass to 
Table III. Average winter values of air pollution and mortality by air mass type (significant values in bold).

\begin{tabular}{|c|c|c|c|c|c|c|c|}
\hline & $\begin{array}{c}\text { Dry } \\
\text { Moderate }\end{array}$ & Dry Polar & $\begin{array}{c}\text { Dry } \\
\text { Tropical }\end{array}$ & $\begin{array}{c}\text { Moist } \\
\text { Moderate }\end{array}$ & $\begin{array}{l}\text { Moist } \\
\text { Polar }\end{array}$ & $\begin{array}{l}\text { Moist } \\
\text { Tropical }\end{array}$ & Transition \\
\hline \multicolumn{8}{|c|}{ Mean Air Pollution with $95 \%$ CI } \\
\hline $\mathrm{CO}(\mathrm{ppm})$ & $1.35 \pm 0.09$ & $1.24 \pm 0.04$ & NC & $1.44 \pm 0.61^{\wedge}$ & $1.23 \pm 0.04$ & $1.83 \pm 0.50^{\wedge}$ & $1.14 \pm 0.05^{\swarrow}$ \\
\hline $\mathrm{NO}_{2}(\mathrm{ppb})$ & $29.2 \pm 1.1^{\wedge}$ & $26.3 \pm 0.6$ & NC & $27.1 \pm 0.8$ & $25.5 \pm 0.6^{2}$ & $27.4 \pm 3.2$ & $24.3 \pm 1.0^{2}$ \\
\hline $\mathrm{SO}_{2}(\mathrm{ppb})$ & $8.6 \pm 0.8^{\wedge}$ & $6.6 \pm 0.5$ & NC & $7.1 \pm 0.5$ & $5.9 \pm 0.5^{-}$ & $7.8 \pm 2.2$ & $6.4 \pm 0.7$ \\
\hline $\mathrm{O}_{3}(\mathrm{ppb})$ & $10.0 \pm 0.7$ & $13.1 \pm 0.4^{\wedge}$ & NC & $6.9 \pm 0.5^{2}$ & $9.9 \pm 0.5^{2}$ & $6.0 \pm 2.3^{2}$ & $12.2 \pm 0.7^{\wedge}$ \\
\hline $\mathrm{PM}_{2.5}\left(\mu \mathrm{g} / \mathrm{m}^{3}\right)$ & $17.0 \pm 1.0$ & $17.5 \pm 0.5$ & NC & $17.1 \pm 0.8$ & $17.5 \pm 0.6$ & $16.5 \pm 3.6$ & $16.7 \pm 1.0$ \\
\hline \multicolumn{8}{|c|}{ Mean Mortality ${ }^{\star}$ and Lags with $95 \%$ CI } \\
\hline Total & $50.3 \pm 1.1$ & $49.6 \pm 0.7^{2}$ & NC & $50.7 \pm 1.0$ & $50.3 \pm 0.8$ & $48.7 \pm 3.4$ & $52.3 \pm 1.1^{\wedge}$ \\
\hline Lag1 & $51.3 \pm 1.2$ & $49.7 \pm 0.7^{2}$ & NC & $50.8 \pm 1.0$ & $50.0 \pm 0.8$ & $48.7 \pm 3.0$ & $51.7 \pm 1.1^{\wedge}$ \\
\hline Lag2 & $51.0 \pm 1.1$ & $50.4 \pm 0.7$ & NC & $50.1 \pm 1.1$ & $50.0 \pm 0.7$ & $48.7 \pm 3.9$ & $51.0 \pm 1.1$ \\
\hline Cardioresp & $24.5 \pm 0.8$ & $24.7 \pm 0.4$ & NC & $25.3 \pm 0.7$ & $24.3 \pm 0.6$ & $24.5 \pm 3.1$ & $26.1 \pm 0.8$ \\
\hline Lag1 & $25.0 \pm 0.8$ & $24.8 \pm 0.5$ & NC & $25.2 \pm 0.7$ & $24.4 \pm 0.7$ & $24.7 \pm 2.4$ & $25.3 \pm 0.8$ \\
\hline Lag2 & $24.8 \pm 0.8$ & $25.1 \pm 0.5$ & NC & $24.6 \pm 0.7$ & $24.5 \pm 0.5$ & $25.5 \pm 2.3$ & $25.3 \pm 0.8$ \\
\hline Other & $25.8 \pm 0.8$ & $24.9 \pm 0.5^{2}$ & NC & $25.4 \pm 0.7$ & $26.0 \pm 0.5$ & $24.1 \pm 3.1$ & $26.2 \pm 0.8$ \\
\hline Lag1 & $26.4 \pm 0.9$ & $24.8 \pm 0.5^{2}$ & NC & $25.6 \pm 0.7$ & $25.6 \pm 0.6$ & $24.0 \pm 2.4$ & $26.4 \pm 0.8^{\wedge}$ \\
\hline Lag2 & $26.2 \pm 0.9$ & $25.3 \pm 0.5$ & NC & $25.5 \pm 0.7$ & $25.5 \pm 0.5$ & $23.3 \pm 2.6$ & $25.7 \pm 0.8$ \\
\hline
\end{tabular}

Bold values indicate mean pollutant or mortality value for synoptic category is significantly statistically different $(p<0.05)$ than the mean according to a two-tailed $t$-test, ${ }^{\wedge}=$ mean is greater than comparison categories, $\stackrel{\nu}{=}$ mean is less than comparison categories; $\mathrm{NC}=$ no comparison due to only one observation.

show consistently strong associations between cardiorespiratory and non-cardiorespiratory mortality and several pollutants: $\mathrm{CO}(\mathrm{RR}=1.266-1.812), \mathrm{NO}_{2}(\mathrm{RR}=1.027-1.044)$, and fine particles $(R R=1.123-1.248)$. The results suggest that in winter, air pollutants were secondary to weather in contributing to increased mortality.

Summer. Toronto's summers most often experience the mild DM air mass, with persistent high pressure systems, warm temperatures and sunny conditions (Table II). The DT and MT air mass categories, together comprising approximately $23 \%$ of all summer days, were the warmest and had the highest mortality rates (Table IV). They also had the highest air pollution concentrations, especially the hot and dry DT category. In contrast significantly lower pollution concentrations were observed in the DP and MP air mass categories, characterized by relatively cool temperatures, with cloudy conditions in the MP category. Unlike in winter, none of the summer categories stood out as having notably lower rates for any of the different causes of mortality (Table IV).

Regression models of all summer days revealed positive associations between total mortality and $\mathrm{CO}(\mathrm{RR}=1.040)$ and $\mathrm{SO}_{2}(\mathrm{RR}=1.004)$ (Table VI). Cardiorespiratory mortality was positively, significantly associated with $\mathrm{SO}_{2}(\mathrm{RR}=1.005)$ and $\mathrm{O}_{3}(\mathrm{RR}=1.002)$ although these effects were quite small. Mortality from non-cardiorespiratory causes was also positively and moderately associated with $\mathrm{CO}(\mathrm{RR}=1.057)$. These results are consistent with previous risk estimates of the association between air pollution and mortality for Toronto, with CO having the largest effect on daily mortality fluctuations (Burnett et al. 1998a).

All summer categories except the TR air mass had at least one positive, significant association between air pollution and one of the causes of mortality (Table VI). Associations were most consistent for the DM category, yet mean pollutant concentrations and mortality 


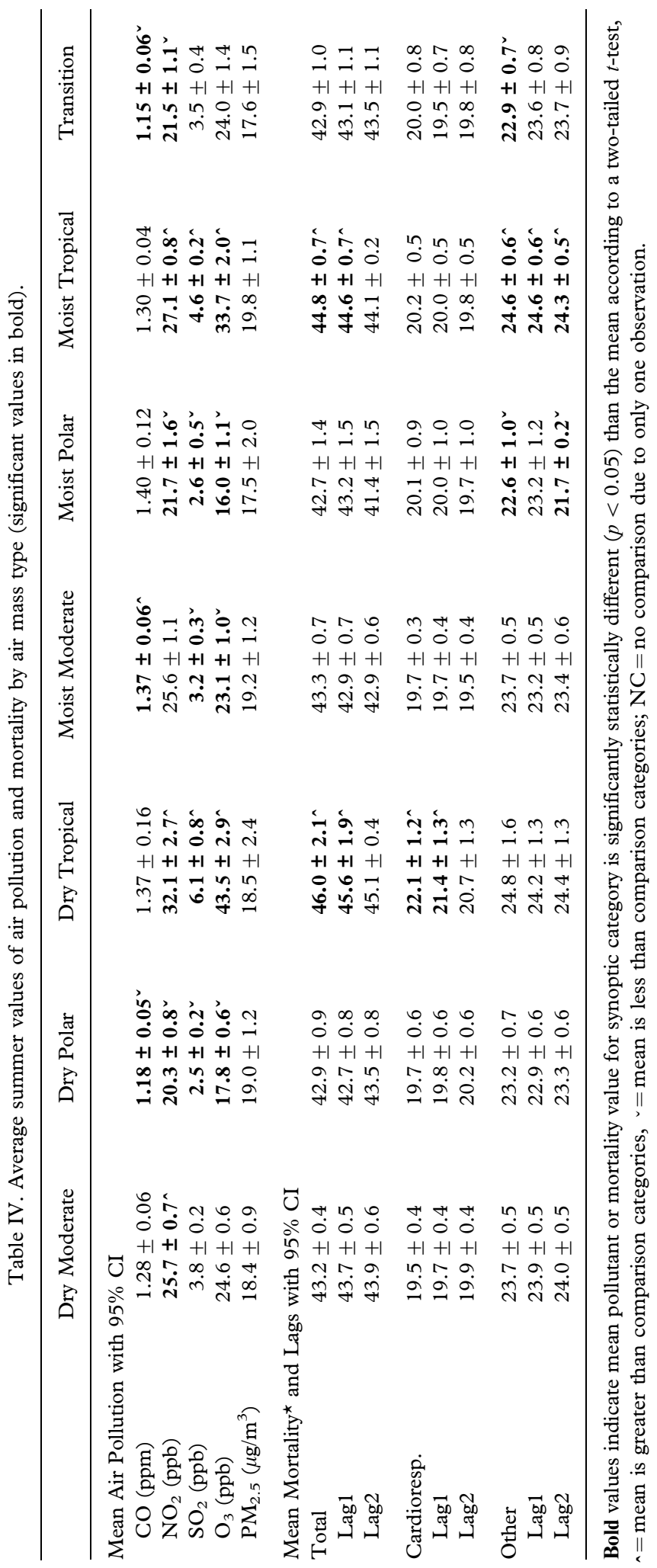




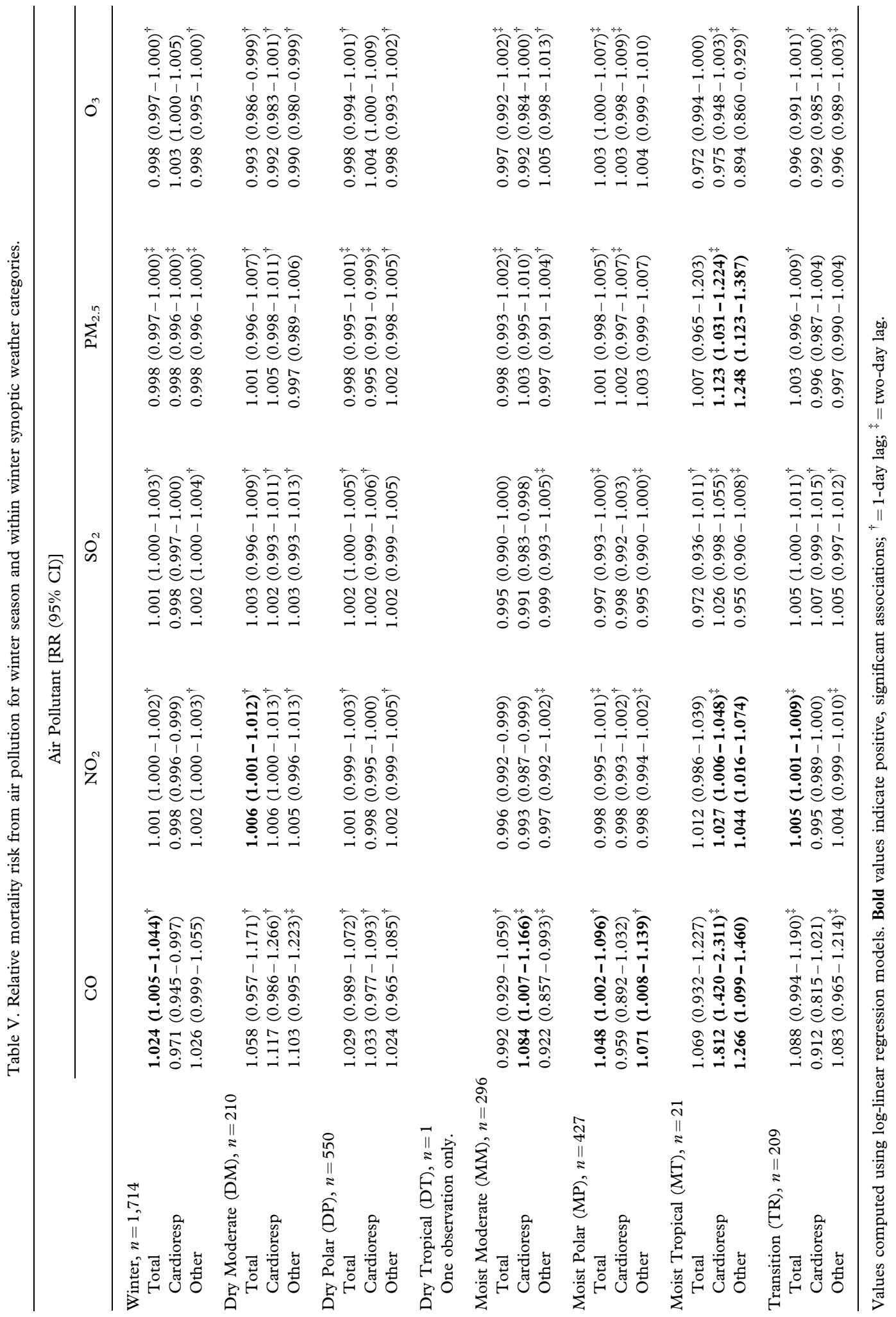




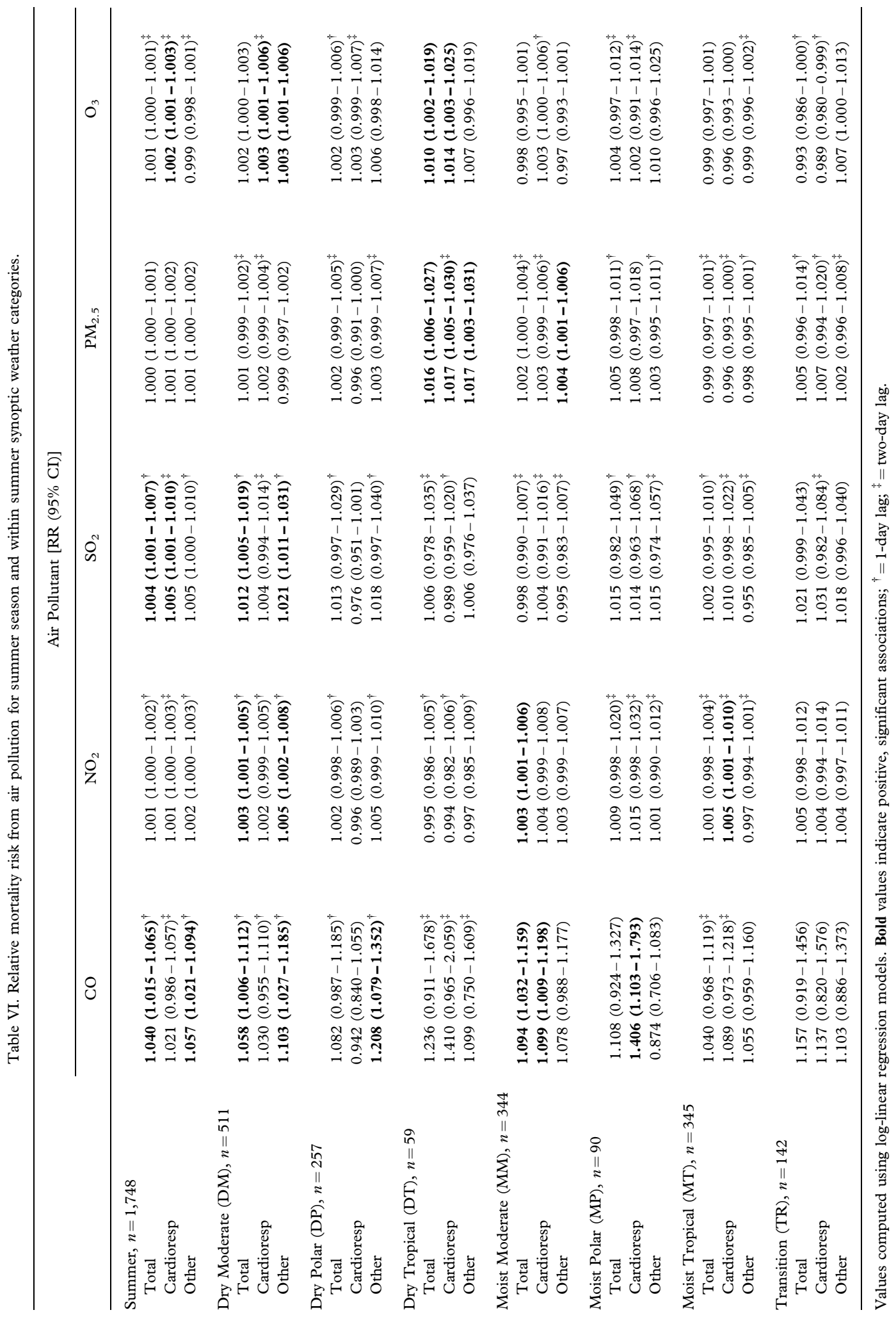


were not significantly different in the DM category than seasonal averages. For example, relative risks for total and non-cardiorespiratory mortality in the DM air mass were 1.058 and 1.103 for $\mathrm{CO}$, and ozone concentrations were significantly associated $(\mathrm{RR}=1.003)$ with both cardiorespiratory and non-cardiorespiratory deaths (Table VI). Although both MT and DT had high pollution levels and mortality rates, air pollution/mortality relationships were stronger in the DT than in the MT air mass. For example, for DT, mortality relative risk point estimates for particulates ranged from 1.016-1.017 depending on mortality cause, and for ozone, 1.010 for total mortality and 1.014 for cardiorespiratory mortality (Table VI). In comparison, only cardiorespiratory mortality had a relationship with a pollutant $\left(\mathrm{NO}_{2}\right)$, with a relative risk point estimate of 1.005 . In summer mean mortality rates and air pollution concentrations varied significantly among air mass types, and there was better concordance between higher concentrations of air pollution and increased mortality than in winter.

\section{Discussion}

\section{Winter}

In winter, Toronto's coldest air mass (DP) had low pollutant concentrations and reduced mortality, contrasting previous research identifying increased winter mortality on days with DP air masses (Kalkstein \& Greene 1997). Our results are more consistent with recent research that suggests day-to-day variation in mortality is associated with additional factors related to the winter season, such as the spread of influenza and comorbid conditions, rather than with colder temperatures (Davis et al. 2004). For example, the transition (TR) air mass was characterized by elevated mortality and lower air pollution concentrations due to dispersion related to instability in the air mass. The higher mortality observed in the TR air mass may be due to inclement weather involving rapid pressure changes and windy conditions, which, have been linked to higher incidence of health impacts such as myocardial infarction and ischemic stroke (Feigin et al. 2000).

Relative mortality risks from air pollution were stronger for the infrequently occurring maritime tropical (MT) air mass than for the other air mass types, especially for CO and $\mathrm{PM}_{2.5}$. There were no clear pollutant/mortality patterns in the other winter synoptic situations. We hypothesize two possible reasons for these results. First, the results are inconsistent across mortality causes and may be spurious due to the small number of days included in the regression models and to the potential for exposure misclassification, since most people are confined indoors in winter. However, there is a plausible link between MT conditions and elevated mortality risk from air pollution. On warmer winter days, people are more likely to be outdoors and thus exposed to air pollution, such as CO, which is composed of ultrafine particles. The pathophysiologic mechanisms of $\mathrm{CO}$ and fine particles are well known (NRC 2004), and humid conditions characteristic of MT air masses have been shown to influence the size, transport, and the biological effects of particles (Flemming 1996).

Furthermore, anticyclonic air masses, in the case of MT air masses dominated by relatively warm, moist conditions, have previously been implicated in excess respiratory admissions and death rates from ischemic heart disease (McGregor et al. 1999), increases in overall mortality (Kalkstein \& Greene 1997) and in sustained pollutant levels (Curson 1996). Laschewski and Jendritzky (2002) found that the sudden moderation of cold conditions in winter was related to increased mortality rates and that re-cooling leads to reduced physiological strain. The apparent susceptibility to air pollution that we found in Toronto during unusually moist and mild winter conditions may be related to weather/pollutant interactions and to physiological 
thermal regulation of sudden changes in weather after acclimatization to typical, colder winter conditions.

The implications of our findings are complex. Our findings that inclement, variable conditions, rather than the coldest air masses, pose the largest health risk correspond with results from comparable studies. Previous research has alluded to the difficulty in determining high risk winter air masses (Kalkstein \& Greene 1997). The role of air pollution in winter mortality in Toronto is unclear, although relative risks were higher from CO than the other pollutants. The primary source of $\mathrm{CO}$ in Toronto is gasoline-powered motor vehicles (Campbell et al. 1995); thus, reducing vehicle emissions could result in lowered winter mortality risk. In addition, climate change could potentially increase the frequency of MT days in winter, which might lead to higher, rather than lower, winter mortality associated with overall warmer winters.

\section{Summer}

Summer results were more intuitive than those for winter. The two hottest air masses (DT and MT) had the highest mortality and air pollution concentrations, which differs from previous research where the hottest air mass had the highest mortality yet relatively average pollutant levels (Smoyer et al. 2000). Dry bulb temperatures in the DT air mass were on average $2^{\circ} \mathrm{C}$ warmer than in the MT air mass, and vapor pressure gradients on DT days can lead to dehydration and hyperthermia due to insufficient perspiration from increased evaporation (Jendritzky 1991). High mortality on MT days is most likely due to high temperatures and humidity levels. Increased humidity and lack of night-time cooling associated with MT conditions may impair physiological abilities to regulate evaporative heat loss by perspiration and vasodilatation. Heat wave research has identified smaller diurnal temperature ranges as a risk factor for increased mortality (Smoyer-Tomic et al. 2003).

Of primary interest in this study is the role of weather in modifying air pollution and mortality associations. The most informative findings were from the hot and high-mortality DT and MT air masses, as well as from the mild MM and DM air masses. Relative mortality risks from air pollution were greater in the DT (notably ozone and fine particulates) than in the MT category, even though both had oppressive weather and high pollution levels. Studies have shown that daily variations in ozone and respirable particulates are associated with mortality rates even after adjustment for temperature (Hoek et al. 2000; Katsouyanni et al. 2001). We hypothesize an interaction between air pollution and temperature, or possibly a multi-pollutant interaction to create more potent mixtures. Previous research has found interactions between ozone and $\mathrm{PM}_{10}$ (Krzyzanowski et al. 1992), and epidemiological investigations show evidence of interactions between relatively high air pollution levels and high temperatures (Katsouyanni et al. 1993; Katsouyanni et al. 2001). Regression results with additional terms to represent potential interactions between temperature and pollutant variables were not significant and not always positive (results not shown), possibly due to reduced statistical power to detect associations.

It is not clear why associations between air pollution and daily mortality were stronger in DT than MT air mass categories even though both categories had high levels of most pollutants. Risk estimates from the MT air mass indicate that air pollution is likely secondary to oppressive weather as the reason for elevated mortality. We hypothesize that MT conditions are more consistently oppressive than DT conditions because of higher dew point temperatures and less variability in diurnal temperatures. Thus the effect of air pollution concentrations (which vary minimally within the MT air mass), may not be detectable above the strong weather/mortality signal. 
Also of interest are the air pollution/mortality relationships in the milder and less polluted DM and MM air masses. Significant, positive associations between most pollutants and mortality were found for days belonging to the DM air mass and for at least one mortality type and CO, $\mathrm{NO}_{2}$, and particulates for the MM category. The stable, comfortable weather conditions associated with the DM air mass are unlikely to affect mortality, and thus the role of air pollution may become more apparent on DM days than when other air masses are present. Furthermore, accuracy of risk estimates of the association between mortality and air pollution may actually be improved since there is less possibility for weather conditions to modify and/or confound model estimates. Given the frequency of the DM and MM air masses (nearly 50\% of all summer days), and the likelihood that exposures may be higher if people spend more time outside (particularly on pleasant DM days), the cumulative effect of air pollution on daily mortality during the relatively benign DM and MM air masses should be explored in more detail.

Numerous epidemiological studies have observed an increase in mortality risk associated with hot, humid weather conditions (Basu \& Samet 2002) and some have suggested that interactions between temperature and air pollutants may produce synergistic effects on health (Smoyer et al. 2000; Katsouyanni et al. 2001). However, our findings such as higher summer mortality risk estimates from air pollution on DT than MT days, despite the hot weather and high mortality characteristic of both synoptic types, reveal the effectiveness of the synoptic approach in capturing the variability of air pollution concentrations, and of air pollution/ mortality relationships, associated with suites of meteorological conditions typical of summer and winter in Toronto.

\section{Conclusions}

The objective of this study was to evaluate the potential for synoptic weather patterns to modify the relationship between ambient air pollutants and mortality for winter and summer in Toronto, Canada. A spatial synoptic climatological procedure was used to develop a daily series of air masses for which values of air pollution and mortality can be calculated. These air masses are a simplified representation of atmospheric conditions, reflecting six dominant suites of meteorological characteristics along with a transition between them, which occur in winter and summer in Toronto. Prevailing patterns of synoptic air masses were identified for winter and summer seasons as well as the average air pollution and human mortality for each category.

Overall, the findings from this investigation strengthen the case that subtle changes in meteorological composition can alter the strength of pollutant associations with health outcomes, especially in the summer season. Although there does not appear to be any systematic patterning of modification, variation in pollutant concentrations seems dependent on the type of synoptic category present. This finding corresponds well to evaluations of air quality according to specific weather types (Flemming 1996; Leighton \& Spark 1997; Cheng \& Lam 2000). There is a need for additional research to improve our understanding of the potential for the totality of atmospheric conditions to impact human health. The results presented here should signal health and environmental policy makers to consider the application of the synoptic approach to reveal atmospheric situations harmful to human wellbeing. Potentially harmful synoptic situations can be identified in advance and appropriate warnings or prevention activities could be enacted to ameliorate human health impacts.

\section{Acknowledgements}

This study was funded by the Adaptation and Impacts Research Group of Environment Canada and the Natural Sciences and Engineering Research Council (NSERC) of Canada. 
The authors also wish to acknowledge the support of the McLaughlin Centre for Population Health Risk Assessment in the Institute of Population Health at the University of Ottawa.

\section{References}

Basu R, Samet JM. 2002. Relation between elevated ambient temperature and mortality: A review of the epidemiologic evidence. Epidemiol Rev 24:190-202.

Burnett RT, Çakmak S, Raizenne ME, Stieb D, Vincent R, Krewski D, Brook JR, Philips O, Ozkaynak H. 1998a. The association between ambient carbon monoxide levels and daily mortality in Toronto Canada. J Air Waste Manage 48:689-700.

Burnett RT, Çakmak S, Brook J. 1998b. The effect of the urban ambient air pollution mix on daily mortality rates in 11 Canadian cities. Can J Pub Health 89:152-156.

Campbell ME, Benson BA, Muir MA. 1995. Urban air quality and human health: A Toronto perspective. Can J Pub Health 86:351-357.

Cheng S, Lam KC. 2000. Synoptic typing and its application to the assessment of climatic impact on concentrations of sulphur dioxide and nitrogen oxides in Hong Kong. Atmos Environ 34:585-594.

Choi K-S, Inoue S, Shinozaki R. 1997. Air pollution, temperature, and regional differences in lung cancer mortality in Japan. Arch Env Health 52:160-168.

Curson P. 1996. Human health, climate and climate change: An Australian perspective. In: Giambelluca T, Henderson-Sellers A, editors. Climate change: Developing southern hemisphere perspectives. Chichester: Wiley. p 475.

Davis RE, Knappenberger PC, Michaels PJ, Novicoff WM. 2004. Seasonality of climate-human mortality relationships in US cities and impacts of climate change. Clim Res 26:61-76.

Dominici F, McDermott A, Zeger SL, Samet JM. 2002. On the use of generalized additive models in time-series studies of air pollution and health. Am J Epidemiol 156:193-203.

Feigin VL, Nikitin YP, Bots ML, Vinogradova TE, Grobbee DE. 2000 A population-based study of the associations of stroke occurrence with weather parameters in Siberia, Russia (1982-1992). Eur J Neurol 7:171-178.

Flemming G. 1996. The importance of air quality in human biometeorology. Int J Biometeorol 39:192-196.

Gotoh T. 1993. Relation between heat islands and $\mathrm{NO}_{2}$ pollution in some Japanese cities. Atmos Environ 27B: $121-128$.

Hoek G, Brunekreef B, Verhoeff A, van Wijnen J, Fischer P. 2000. Daily mortality and air pollution in the Netherlands. J Air Waste Man Assoc 50:1380 - 1389.

Jendritzky G. 1991. Selected questions of topical interest in human bioclimatology. Int J Biometeorol 35 : $139-150$.

Kalkstein LS, Tan G, Skindlov J. 1987. An evaluation of objective clustering procedures for use in synoptic climatological classification. J Clim Appl Meteorol 26:717-730.

Kalkstein LS, Greene JS. 1997. An evaluation of climate/mortality relationships in large U.S. cities and possible impacts of climate change. Environ Health Perspect 105:84-93.

Katsouyanni K, Pantazopoulou A, Touloumi G, Tselepidaki I, Moustris K, Asimakopoulos D, Poulopoulou G, Trichopoulos D. 1993. Evidence for interaction between air pollution and high temperature in the causation of excess mortality. Arch Env Health 48:235-242.

Katsouyanni K, Touloumi G, Samoli E, Gryparis A, Le Tertre A, Monopolis Y, Rossi G, Zmirou D, Ballester F, Boumghar A, et al. 2001. Confounding and effect modification in the short-term effects of ambient particles on total mortality: results from 29 European cities within the APHEA2 project. Epidemiology 12:521 -531.

Krzyzanowski M, Quakenboss JJ, Lebowitz MD. 1992. Relation of peak expiratory flow rates and symptoms to ambient ozone. Arch Environ Health 46:262-270.

Laschewski G, Jendritzky G. 2002. Effects on the thermal environment on human health: An investigation of 30 years of daily mortality data from SW Germany. Clim Res 21:91-103.

Lam K-C, Cheng S. 1998. A synoptic climatological approach to forecast concentrations of sulphur dioxide and nitrogen oxides in Hong Kong. Environ Pollution 101:183-191.

Lebowitz MD, Cassell EJ, McCarroll JD. 1973. Health and the urban environment. XV. Acute respiratory episodes as reaction by sensitive individuals to air pollution and weather. Environ Res 5:135-141.

Leighton RM, Spark E. 1997. Relationship between synoptic climatology and pollution events in Sydney. Int J Biometeorol 41:76-89.

McGregor GR, Walters S, Wordley J. 1999. Daily hospital respiratory admissions and winter air mass types, Birmingham, UK. Int J Biometeorol 43:21-30. 
NRC (National Research Council) 2004. Research priorities for airborne particulate matter: IV. Continuing research progress. Committee on Research Priorities for Airborne Particulate Matter, National Research Council. Washington, DC: National Academies Press.

Niccum EM, Lehrman DE, Knuth WR. 1995. The influence of meteorology on the air quality in the San Luis Obispo County-South-western San Joaquin Valley region for 3-6 August 1990. J Appl Meteorol 34:1834-1847.

O’Neill MS, Zanobetti A, Schwartz J. 2003. Modifiers of the temperature and mortality association in seven US cities. Am J Epidemiol 157:1074-1082.

Pattenden S, Nikiforov B, Armstrong BG. 2003. Mortality and temperature in Sofia and London. J Epidemiol Comm Health 57:628-633.

Pope CA, Kalkstein LS. 1996. Synoptic weather modelling and estimates of the exposure-response relationship between daily mortality and particulate air pollution. Environ Health Perspect 104:414-420.

Rainham DG, Smoyer-Tomic KE. 2003. The role of air pollution in the relationship between a heat stress index and human mortality in Toronto. Environ Res 93:9-19.

Ramsey T, Burnett RT, Krewski D. 2002. Underestimation of standard errors in generalized additive models linking mortality to ambient particulate matter. Epidemiology 14:18-23.

Samet JM, Dominici F, Curriero FC, Coursac I, Zeger SL. 2000. Fine particulate air pollution and mortality in 20 U.S. cities, 1987-1994. N Engl J Med 343:1742-1749.

Sheridan SC. 2002. The redevelopment of a weather-type classification scheme for North America. Int J Clim 22: $51-68$.

Smoyer KE, Kalkstein LS, Green JS, Ye H. 2000. The impacts of weather and air pollution on human mortality in Birmingham, Alabama and Philadelphia, Pennsylvania. Int J Clim 20:881-897.

Smoyer-Tomic KE, Kuhn R, Hudson A. 2003. Heat wave hazards: An overview of heat wave impacts in Canada. Natural Hazards 28:463-485.

Styer P, McMillan N, Gao F, Davis J, Sachs J. 1995. Effect of outdoor airborne particulate matter on daily death counts. Environ Health Perspect 103:490-497.

Wyzga RE, Lipfert FW. 1994. Ozone and daily mortality: the ramifications of uncertainties and interactions and some initial regression results. AWMA Conference on Tropospheric Ozone. Orlando, FL: Air and Waste Management Association. 